BNL-114117-2017-JA

\title{
Highly Active Pt/MoC and Pt/TiC Catalysts for the Low- Temperature Water-gas Shift Reaction: Effects of the Carbide Metal/Carbon Ratio on the Catalyst Performance
}

\author{
J. A. Rodriguez, P. J. Ramírez, and R. A. Gutiérrez
}

Submitted to Catalysis Today

July 2017

Chemistry Department

Brookhaven National Laboratory

\author{
U.S. Department of Energy \\ USDOE Office of Science (SC), \\ Basic Energy Sciences (BES) (SC-22)
}

Notice: This manuscript has been authored by employees of Brookhaven Science Associates, LLC under Contract No. DE- SC0012704 with the U.S. Department of Energy. The publisher by accepting the manuscript for publication acknowledges that the United States Government retains a non-exclusive, paid-up, irrevocable, world-wide license to publish or reproduce the published form of this manuscript, or allow others to do so, for United States Government purposes. 


\section{DISCLAIMER}

This report was prepared as an account of work sponsored by an agency of the United States Government. Neither the United States Government nor any agency thereof, nor any of their employees, nor any of their contractors, subcontractors, or their employees, makes any warranty, express or implied, or assumes any legal liability or responsibility for the accuracy, completeness, or any third party's use or the results of such use of any information, apparatus, product, or process disclosed, or represents that its use would not infringe privately owned rights. Reference herein to any specific commercial product, process, or service by trade name, trademark, manufacturer, or otherwise, does not necessarily constitute or imply its endorsement, recommendation, or favoring by the United States Government or any agency thereof or its contractors or subcontractors. The views and opinions of authors expressed herein do not necessarily state or reflect those of the United States Government or any agency thereof. 


\title{
Highly Active Pt/MoC and Pt/TiC Catalysts for the Low-Temperature Water-gas Shift Reaction: Effects of the Carbide Metal/Carbon Ratio on the Catalyst Performance
}

\author{
José A. Rodriguez, ${ }^{1, *}$ Pedro J. Ramírez, ${ }^{1,2}$ and Ramón A. Gutiérrez. ${ }^{2}$ \\ 1: Chemistry Department, Brookhaven National Laboratory, Upton, NY, 11973 (USA) \\ 2: Facultad de Ciencias, Universidad Central de Venezuela, Caracas 1020-A, Venezuela
}

\begin{abstract}
$\mathrm{Pt} / \mathrm{MoC}$ and $\mathrm{Pt} / \mathrm{TiC}(001)$ are excellent catalysts for the low-temperature water-gas shift (WGS, $\mathrm{CO}+\mathrm{H}_{2} \mathrm{O} \rightarrow \mathrm{H}_{2}+\mathrm{CO}_{2}$ ) reaction. They exhibit high-activity, stability and selectivity. The highest catalytic activities are seen for small coverages of $\mathrm{Pt}$ on the carbide substrates. Synergistic effects at the metal-carbide interface produce an enhancement in chemical activity with respect to pure $\mathrm{Pt}, \mathrm{MoC}$ and $\mathrm{TiC}$. A clear correlation is found between the ability of the $\mathrm{Pt} / \mathrm{MoC}$ and $\mathrm{Pt} / \mathrm{TiC}(001)$ surfaces to partially dissociate water and their catalytic activity for the WGS reaction. An overall comparison of the results for $\mathrm{Pt} / \mathrm{MoC}$ and $\mathrm{Pt} / \mathrm{Mo}_{2} \mathrm{C}(001)$ indicates that the metal/carbon ratio in the carbide support can have a strong influence in the stability and selectivity of WGS catalysts and is a parameter that must be taken into consideration when designing these systems.
\end{abstract}

Keywords: Water; Water-gas shift; Hydrogen production; Platinum; Molybdenum carbide; Titanium carbide.

* To whom correspondence should be addressed.

E-mail. Rodrigez@bnl.gov

Phone: (631) 344-2246

FAX: (631) 344-5815 


\section{Introduction}

The industrial production of hydrogen as a feedstock usually involves the steam reforming (SR) of methane and other hydrocarbons [1]. New raw materials, such as biomass or waste, also can be used for reforming purposes [1]. The hydrogen produced by the SR process usually contains small amounts (1-5\%) of $\mathrm{CO}$ as an impurity. The water-gas shift reaction (WGS, $\mathrm{CO}+\mathrm{H}_{2} \mathrm{O} \rightarrow \mathrm{H}_{2}+\mathrm{CO}_{2}$ ) is a convenient route to remove the $\mathrm{CO}$ and produce additional hydrogen [2,3]. Mixtures of $\mathrm{Fe}-\mathrm{Cr}$ and $\mathrm{Zn}-\mathrm{Al}-\mathrm{Cu}$ oxides are frequently the commercially used catalysts for the WGS reaction at temperatures between $350-500$ and $180-250{ }^{0} \mathrm{C}$, respectively. However, these oxide catalysts are pyrophoric and frequently require lengthy and complex activation steps before they are used $[2,3]$. Consequently new catalysts are being sought.

In recent years, it has become clear that metals supported on metal-carbides can be good catalysts for the WGS reaction $[4,5,6]$. A systematic study has been carried out examining the performance of several metals ( $\mathrm{Pt}, \mathrm{Pd}, \mathrm{Ni}, \mathrm{Au}, \mathrm{Ag}$ and $\mathrm{Cu}$ ) supported over $\mathrm{Mo}_{2} \mathrm{C}$ for the WGS reaction [5]. It was found that the reactivity of the catalysts increased in the sequence: $\mathrm{Mo}_{2} \mathrm{C}<\mathrm{Ag} / \mathrm{Mo}_{2} \mathrm{C}<\mathrm{Cu} / \mathrm{Mo}_{2} \mathrm{C}<\mathrm{Ni} / \mathrm{Mo}_{2} \mathrm{C}<\mathrm{Pd} / \mathrm{Mo}_{2} \mathrm{C}<\mathrm{Au} / \mathrm{Mo}_{2} \mathrm{C}<$ $\mathrm{Pt} / \mathrm{Mo}_{2} \mathrm{C}$ [5]. The $\mathrm{Pt} / \mathrm{Mo}_{2} \mathrm{C}$ catalysts exhibited an activity that was 4-8 times than that found for a commercial $\mathrm{Cu} / \mathrm{ZnO} / \mathrm{Al}_{2} \mathrm{O}_{3}$ catalyst [5]. In fact, it was shown that $\mathrm{Pt} / \mathrm{Mo}_{2} \mathrm{C}$ has an activity higher than that of any Pt/oxide catalyst studied [4,5]. On the other hand, a basic study has shown that $\operatorname{Pt}(111)$ has a moderate activity for the water-gas shift reaction and exhibits a tendency to deactivate via carbon deposition by the Boudouard reaction $\left(2 \mathrm{CO} \rightarrow \mathrm{C}+\mathrm{CO}_{2}\right)$ [7]. This suggests that metal-support interactions may be modifying the intrinsic chemistry of platinum in the $\mathrm{Pt} / \mathrm{Mo}_{2} \mathrm{C}$ catalysts. It is known that metal 
carbides are non-innocent supports and can modify the electronic and chemical properties of admetals $[4,8]$. Indeed, results of density functional calculations indicate that Pt atoms in contact with a $\delta$-MoC(001) surface have a negative charge $[8,9]$.

An important parameter to check when dealing with the design of metal carbide catalysts is the metal/carbon atomic ratio in the system $[10,11,12]$. In general, a decrease in the metal/carbon ratio in a carbide usually reduces the reactivity of the system as a consequence of electronic - a raise in the positive charge on the metal centers - and structural effects - a reduction in the number of metal centers exposed on the carbide surface. This drop in reactivity makes the carbide less sensitive to attack by oxygen $[6,8]$. In principle, the metal/carbon ratio could have an effect in the activity, selectivity and stability of a metal carbide catalyst $[10,11,12]$. In this study, we move from $\mathrm{Mo}_{2} \mathrm{C}$ as a substrate to two carbides that have a 1:1 metal/carbon ratio: $\mathrm{MoC}$ and $\mathrm{TiC}$. To the best of our knowledge, powders of these carbides have not been used as a catalyst for the WGS. $\mathrm{Au} / \mathrm{TiC}(001)$ exhibits catalytic activity and is useful as point of reference.[6] In the $\mathrm{Pt} / \mathrm{MoC}$ and $\mathrm{Pt} / \mathrm{TiC}$ systems, we find evidence for synergistic interactions involving the metal and carbide support. These interactions help with the dissociation of water and produce excellent WGS catalysts. Over $\mathrm{Pt} / \mathrm{MoC}$ and $\mathrm{Pt} / \mathrm{TiC}$, there is no production of methane as a side product, as occurs in the case of $\mathrm{Pt} / \mathrm{Mo}_{2} \mathrm{C}$, and the catalysts do not deactivate by the formation of an oxycarbide.

\section{Experimental}

We investigated the performance for the water-gas shift of a series of catalysts generated by the deposition of $\mathrm{Pt}$ on $\mathrm{TiC}(001)$, polycrystalline $\delta$-MoC, and $\beta-\mathrm{Mo}_{2} \mathrm{C}(001)$ 
surfaces. The experimental data were collected in an instrument that combined an ultrahigh vacuum (UHV) chamber for surface characterization and a micro-reactor for catalytic tests $[6,13]$. The UHV chamber was equipped with instrumentation for X-ray photoelectron spectroscopy (XPS), low-energy electron diffraction (LEED), ionscattering spectroscopy (ISS), and thermal-desorption mass spectroscopy (TDS) [6,13].

The $\mathrm{TiC}(001)$ and $\beta-\mathrm{Mo}_{2} \mathrm{C}(001)$ surfaces were prepared and cleaned as described in previous works $[6,14]$. The $\delta$-MoC examined in this study is best described as polycrystalline [15]. Surface impurities were removed by $\mathrm{Ar}^{+}$sputtering, and a C/Mo ratio close to 1 was restored by exposing this surface to $\mathrm{C}_{2} \mathrm{H}_{2}$ or $\mathrm{C}_{2} \mathrm{H}_{4}$ at $800-900 \mathrm{~K}$ [15]. Several attempts were made to prepare well-defined surfaces of $\delta$-MoC oriented along the (001) plane of this carbide. However, it was not possible to prepare an ideal $\delta$ $\mathrm{MoC}(001)$ surface. The preparation of this particular surface is very difficult due to the complex phase diagram of MoC [11,15]. Pt was vapor deposited on the metal carbide substrates at $300 \mathrm{~K}$

In the kinetic measurements the sample was transferred to the batch reactor at $300 \mathrm{~K}$, then the reactant gases were introduced ( 20 Torr of $\mathrm{CO}$ and 10 Torr of $\mathrm{H}_{2} \mathrm{O}$ ) and the sample was rapidly heated to the reaction temperatures investigated $(410,425,435$, $450,465 \mathrm{~K})$. The amount of molecules produced was normalized by the active area exposed by the sample $[6,13]$. In our reactor a constant rate for the production of $\mathrm{H}_{2}$ and $\mathrm{CO}_{2}$ was reached after 2-3 minutes of reaction time. The kinetic measurements were done at the limit of low conversion $(<5 \%)$. The $\mathrm{CO}$ gas was cleaned of any metal carbonyl impurity by passing it through purification traps $[6,13]$. 


\section{Results and Discussions}

\subsection{Performance and stability of $\mathrm{Pt} / \mathrm{MoC}$ and $\mathrm{Pt} / \mathrm{TiC}(001)$ WGS catalysts}

The left-side panel in Figure 1 shows O 1s XPS spectra collected after dosing 50 Langmuir (L) of water to clean MoC and a surface pre-covered with 0.15 ML of platinum at $300 \mathrm{~K}$. In both spectra, there is a single peak at a binding energy of $\sim 531.6 \mathrm{eV}$. This binding energy corresponds to $\mathrm{OH}$ groups [16] produced by the dissociation of water. Clean $\mathrm{MoC}$ is not very reactive and exposure to water produces a small amount of $\mathrm{OH}$ groups, $\sim 0.08$ monolayer $(\mathrm{ML})$, on the surface. $\operatorname{Pt}(111)$ also does not interact well with water [7], since the dissociation process of the molecule is hampered by a large activation barrier [7,13]. In contrast, the $\mathrm{Pt} / \mathrm{MoC}$ system reacts well with the water molecule producing a large amount of adsorbed $\mathrm{OH}$. Thus, there is a synergy at the Pt-carbide interface that helps with the dissociation of water. As shown in the right-side panel of Figure 1, the reactivity of the system depends strongly on the coverage of $\mathrm{Pt}$ on the surface. As Pt is added, a maximum in activity is seen at 0.15-0.2 ML. Thus, high activity probably involves small particles of Pt in close contact with MoC. Results of density functional calculations show a substantial negative charge on Pt atoms bonded to a $\delta$ MoC(001) surface [9]. The electronic perturbations on the Pt adatoms probably affect their chemical behavior.

Experiments were also conducted for the reaction of water with $\mathrm{Pt} / \mathrm{TiC}(001)$ surfaces obtaining results very similar to those shown for $\mathrm{Pt} / \mathrm{MoC}$, but the reactivity towards water was a little bit smaller (Figure 1). Water dissociation is a rate limiting step for the WGS reaction on $\operatorname{Pt}(111)[7,13,17,18]$ and on many other metal surfaces 
$[19,20,21]$. Over $\operatorname{Pt}(111)$, the slow dissociation of water is problematic because the main channel for the WGS eventually cannot compete with the Boudouard reaction and there is deactivation of the catalyst by carbon deposition [7]. This may not be a problem on $\mathrm{Pt} / \mathrm{MoC}$ and $\mathrm{Pt} / \mathrm{TiC}$ due to the fast dissociation of water. On these surfaces, there is a relatively large reservoir of $\mathrm{OH}$ groups that can react with $\mathrm{CO}$ to give an $\mathrm{HOCO}$ intermediate $[17,19,20]$ and $\mathrm{CO}_{2}$ and $\mathrm{H}_{2}$ as products of the WGS.

Figure 2 shows the WGS catalytic activity for a series of Pt/MoC catalysts at 450 $\mathrm{K}$. Clean $\mathrm{MoC}$ has a limited activity for catalyzing the reaction. A clear improvement is seen upon the addition of Pt. The trends in Figure 2 match the trends in Figure 1 for the dissociation of water. At Pt coverages of $0.15-0.2$ ML a maximum in the rate of water dissociation and in the production of $\mathrm{H}_{2}$ and $\mathrm{CO}_{2}$ is seen. The chemical and catalytic activity of the $\mathrm{Pt} / \mathrm{MoC}$ system decrease when the Pt coverage is large probably due to the formation of large three-dimensional (3D) particles of the admetal in which the atoms are not part of the Pt-carbide interface. Small platinum particles in close contact with the carbide are the best catalysts. An identical result was obtained for the deposition of Pt on the $\mathrm{TiC}(001)$ substrate. Again a maximum in catalytic activity was seen at $0.15-0.2 \mathrm{ML}$ and there was a strong correlation with the ability displayed by the $\mathrm{Pt} / \mathrm{TiC}(001)$ surface to dissociate water.

Figure 3 displays Arrhenius plots for the WGS reaction on $\mathrm{Pt} / \mathrm{MoC}$ and $\mathrm{Pt} / \mathrm{TiC}(001)$ catalysts $\left(\theta_{\mathrm{Pt}}=0.15 \mathrm{ML}\right)$. Since $\mathrm{Cu}$-based catalysts are frequently employed in the WGS process $[2,3,19,20,22]$, we also include for comparison data for a $\mathrm{Cu} / \mathrm{TiC}(001)$ catalyst [22]. In agreement with a previous study comparing the activity of $\mathrm{Pt} / \mathrm{Mo}_{2} \mathrm{C}$ and $\mathrm{Cu} / \mathrm{Mo}_{2} \mathrm{C}$ powder catalysts [5], we find that the $\mathrm{Pt} / \mathrm{MoC}$ and $\mathrm{Pt} / \mathrm{TiC}(001)$ 
systems have a better performance than the $\mathrm{Cu} / \mathrm{TiC}(001)$ catalyst. On the platinum-based systems, the apparent activation energies are $-9.1 \quad\{\mathrm{Pt} / \mathrm{MoC}\}$ and $-9.4 \mathrm{kcal} / \mathrm{mol}$ $\{\mathrm{Pt} / \mathrm{TiC}(001)\}$. These values are much smaller than the apparent activation energy of $22.9 \mathrm{kcal} / \mathrm{mol}$ reported on a $\mathrm{Pt}(111)$ single crystal [7]. The synergistic interactions at the Pt-carbide interface that favor dissociation of water are probably responsible for this large drop in the apparent activation energy. Apparent activation energies of 11.5 and 12.7 $\mathrm{kcal} / \mathrm{mol}$ have been reported for $\mathrm{Pt} / \mathrm{Mo}_{2} \mathrm{C}$ powder catalyst [4,5].

From the data in Figure 3, we calculated turnover frequencies (TOFs) for $\mathrm{Pt} / \mathrm{MoC}$ and $\mathrm{Pt} / \mathrm{TiC}(001)$, Figure 4, on the assumption that all platinum atoms in the catalytic surfaces were involved in the WGS process. Since the Pt coverage was small, 0.15 ML, this assumption is probably a very good approximation. The TOFs in Figure 4 indicate that our $\mathrm{Pt} / \mathrm{MoC}$ and $\mathrm{Pt} / \mathrm{TiC}(001)$ catalysts have a higher activity than the best catalysts reported in the literature for the low-temperature WGS reaction $[3,4,5]$, although a quantitative comparison of the performance is difficult due to differences in morphology and in the reaction conditions.

Figure 5 compares estimated TOFs for $\mathrm{Pt} / \mathrm{MoC}, \mathrm{Pt} / \mathrm{TiC}(001)$ and $\mathrm{Cu} / \mathrm{TiC}(001)$ with those reported for well-defined catalysts such as $\mathrm{Cu}(111), \operatorname{Pt}(111)$, and $\mathrm{Cu} / \mathrm{ZnO}(000 \overline{1})[7,22,23,24,25]$. This set of catalysts has a very poor performance at temperatures below $500 \mathrm{~K}[7,22,23,24,25]$. At $612 \mathrm{~K}, \mathrm{Cu}(111), \operatorname{Pt}(111)$, and $\mathrm{Cu} / \mathrm{ZnO}(000 \overline{1})$ have TOFs which are 5-10 times smaller than those of $\mathrm{Pt} / \mathrm{MoC}$ and $\mathrm{Pt} / \mathrm{TiC}(001)$ at a much lower temperature of $450 \mathrm{~K}$. In terms of net activity, $\mathrm{Cu} / \mathrm{ZnO}(000 \overline{1})$ [25], which is a model for an industrial $\mathrm{Cu} / \mathrm{ZnO}$ catalyst $[2,3]$, does not 
compete well with $\mathrm{Pt} / \mathrm{MoC}$ and $\mathrm{Pt} / \mathrm{TiC}(001)$. These catalysts are also better than the $\mathrm{Au} / \mathrm{TiC}(001)$ system examined in a previous study [6].

An important issue when dealing with the use of metal carbides as possible catalysts for the WGS is stability. Reaction of the carbide with water can lead to the formation of an oxycarbide and a reduction in catalytic activity $[11,26]$. We found that the $\mathrm{Pt} / \mathrm{MoC}$ and $\mathrm{Pt} / \mathrm{TiC}(001)$ systems were stable under WGS reaction conditions at temperatures below $470 \mathrm{~K}$. Under these conditions the amount of oxygen or oxygencontaining species deposited on the surface of the carbide was small and did not change with time (Figure 6). A different behavior was seen at temperatures above $500 \mathrm{~K}$ : The uptake of oxygen was larger and increased with time (Figure 6). Two phenomena may contribute to this change in stability. On one hand, the formation of oxycarbides from water may have to overcome an activation barrier to rearrange the structure of the $\mathrm{MoC}$ or TiC. On the other hand, at elevated temperatures there may be a rupture in the catalytic cycle and the oxygen or $\mathrm{OH}$ groups deposited by water dissociation are not removed in an efficient way by reaction with $\mathrm{CO}$. Instead of forming $\mathrm{CO}_{2}$ gas, the oxygen or $\mathrm{OH}$ groups react with the carbide substrate.

A previous study using density-functional calculations found that Pt atoms in contact with $\mathrm{TiC}(001)$ and $\delta$-MoC(001) are electronically perturbed.[8,9] They receive electrons from the carbide substrates.[9] The extra charge on the admetal atoms favors interactions with $\mathrm{CO}$ and water,[12,13] making the $\mathrm{Pt} / \mathrm{TiC}$ and $\mathrm{Pt} / \mathrm{MoC}$ systems more reactive than $\mathrm{Pt}(111)$. Furthermore, corner and edge atoms present in $\mathrm{Pt}$ nanoparticles have a tendency to make then more active for $\mathrm{O}-\mathrm{H}$ bond cleavage than $\mathrm{Pt}(111)$.[13] The 
WGS chemistry also could occur at the Pt-carbide interface with the water molecule dissociating on the carbide side and CO bound to the Pt metal.[6]

\subsection{Performance and stability of $\mathrm{Pt} / \mathrm{Mo}_{2} \mathrm{C}(001)$ WGS catalysts}

The left-side panel in Figure 7 shows an O 1s XPS spectrum recorded after dosing $50 \mathrm{~L}$ of water to a $\beta-\mathrm{Mo}_{2} \mathrm{C}(001)$ surface at $300 \mathrm{~K}$. A broad peak is observed which can be separated in two features. The feature near $530 \mathrm{eV}$ matches the binding energy seen in our instrument after depositing atomic $\mathrm{O}$ on the $\beta-\mathrm{Mo}_{2} \mathrm{C}(001)$ surface. This feature is probably the product of the full decomposition of water $\left(\mathrm{H}_{2} \mathrm{O} \rightarrow \mathrm{O}+2 \mathrm{H}\right)$ on the carbide substrate. A second feature is seen near $531.5 \mathrm{eV}$ which probably corresponds to $\mathrm{OH}$ groups [16] generated by the partial dissociation of water. Under the same reaction conditions only a small amount of $\mathrm{OH}$ is detected on a MoC surface. From the uptake curves in the right-side panel of Figure 7 , it is clear that $\beta-\mathrm{Mo}_{2} \mathrm{C}(001)$ is much more reactive towards water than MoC. This is probably a consequence of ligand (electronic) and ensemble (structural) effects [26]. In MoC, the positive charge on the Mo centers is larger than in $\beta-\mathrm{Mo}_{2} \mathrm{C}(001)[14,26]$ and the number of Mo atoms exposed in the surfaces of the 1:1 carbide is smaller. These two factors moderate the reactivity of MoC towards water.

The large affinity that $\beta-\mathrm{Mo}_{2} \mathrm{C}(001)$ has for water can be problematic since these surface binds $\mathrm{OH}$ and $\mathrm{O}$ strongly $[11,27]$. In fact, theoretical calculations predict that this surface is not stable under WGS reaction conditions [26]. The active phase should contain a layer of atomic oxygen on top of the carbide surface [26]. We investigated the stability of a catalyst generated by depositing $0.15 \mathrm{ML}$ of $\mathrm{Pt}$ on a clean $\beta-\mathrm{Mo}_{2} \mathrm{C}(001)$ 
substrate. Figure 8 shows how the content of $\{\mathrm{O}+\mathrm{OH}\}$ on the $\mathrm{Pt} / \mathrm{Mo}_{2} \mathrm{C}(001)$ surface changes as a function of time under WGS reaction conditions at $450 \mathrm{~K}$. The coverage of $\{\mathrm{O}+\mathrm{OH}\}$ on $\mathrm{Pt} / \mathrm{Mo}_{2} \mathrm{C}(001)$ is much larger than on $\mathrm{Pt} / \mathrm{MoC}$ and increases continuously with time leading to problems of catalyst stability. Our results for $\mathrm{Pt} / \mathrm{Mo}_{2} \mathrm{C}(001)$, and those obtained for a $\mathrm{Pt} / \mathrm{Mo}_{2} \mathrm{C}$ powder catalyst [5], point to an active phase in which nanoparticles of $\mathrm{Pt}$ are dispersed on the surface of an oxycarbide.

In many industrial operations, the WGS process is carried out under hydrogenrich conditions with mixtures of $\mathrm{CO} / \mathrm{H}_{2} \mathrm{O} / \mathrm{H}_{2}$ originated by the reforming of hydrocarbons [1-3,4,28]. The dissociation of $\mathrm{CO}$ on $\mathrm{MoC}$ and $\mathrm{TiC}(001)$ is an uphill process [6,14], but the $\beta-\mathrm{Mo}_{2} \mathrm{C}(001)$ surface can dissociate the molecule [14,27]. Under hydrogen-rich conditions, $\beta-\mathrm{Mo}_{2} \mathrm{C}(001)$ can transform $\mathrm{CO}$ into methane [14,27]. This is problematic for the selectivity towards hydrogen production through the WGS process. Figure 9 compares the product distribution after exposing fresh $\mathrm{Pt} / \mathrm{MoC}$ and $\mathrm{Pt} / \mathrm{Mo}_{2} \mathrm{C}(001)$ catalysts to a mixture of $\mathrm{CO}\left(20\right.$ Torr) and $\mathrm{H}_{2} \mathrm{O}$ (10 Torr) at $435 \mathrm{~K}$. The amount of $\mathrm{CO}_{2}$ produced on both catalysts is comparable but on $\mathrm{Pt} / \mathrm{Mo}_{2} \mathrm{C}(001)$ there is also methane production.

An overall comparison of the results for $\mathrm{Pt} / \mathrm{MoC}$ and $\mathrm{Pt} / \mathrm{Mo}_{2} \mathrm{C}(001)$ indicates that the metal/carbon ratio in the carbide support can have a strong influence in the stability and selectivity of WGS catalysts and is a parameter that must be taken into consideration when designing these systems.

\section{Conclusions}


$\mathrm{Pt} / \mathrm{MoC}$ and $\mathrm{Pt} / \mathrm{TiC}(001)$ are excellent catalysts for the low-temperature water-gas shift reaction. They exhibit high-activity, stability and selectivity. In terms of performance at low temperature, they are orders of magnitude better than the typical industrial $\mathrm{Cu} / \mathrm{ZnO}$ catalyst.

The highest catalytic activities are seen for small coverages of Pt on the carbide substrates. Synergistic effects at the metal-carbide interface produce an enhancement in chemical activity with respect to pure $\mathrm{Pt}, \mathrm{MoC}$ and $\mathrm{TiC}$. A clear correlation is found between the ability of the $\mathrm{Pt} / \mathrm{MoC}$ and $\mathrm{Pt} / \mathrm{TiC}(001)$ surfaces to partially dissociate water and their catalytic activity for the WGS reaction.

The metal/carbon ratio in the carbides has a strong effect in the stability and selectivity of $\mathrm{Pt} / \mathrm{MoC}$ and $\mathrm{Pt} / \mathrm{TiC}(001)$. In this $1: 1$ carbides, the positive charge on the metal centers is larger than in a $\mathrm{Mo}_{2} \mathrm{C}$ carbide and the number of metal atoms exposed in their reactive surfaces is limited. These two factors moderate the reactivity of $\mathrm{MoC}$ and TiC leading to a very good performance in the WGS process.

\section{Acknowledgements}

The work at BNL was supported by the U.S. Department of Energy, Office of Basic Energy Sciences, Chemical Science Division (DE-SC0012704). P.R.J. is grateful to INTEVEP for partial support of the work carried out at UCV. 


\section{References:}

1. K. Liu, C. Song and V. Subramani, Hydrogen and Syngas Production and Purification Technologies, Wiley: New York, 2010.

2. M. S. Spencer, Topics in Catalysis 8 (1999) 259

3. R.B. Burch, Phys. Chem. Chem. Phys. 8 (2006) 5483.

4. N.M. Schweitzer, J.A. Schaidle, O.K. Ezekoye, X. Pan, S. Linic, and L.T. Thompson, J. Am. Chem. Soc. 133 (2011) 2378-2381.

5. K.D. Sabnis, Y. Cui, M.C. Akatay, M. Shekhar, W.-S. Lee, J.T. Miller, W.N. Delgass, and F.H. Ribeiro, J. Catal. 331 (2015) 162.

6. J.A. Rodriguez, P.J. Ramirez, G.G. Asara, F. Viñes, J. Evans, P. Liu, J.M. Ricart, and F. Illas, Angew. Chem. In. Ed. 53 (2014) 11270.

7. D.W. Flaherty, W.-Y. Yu, Z.D. Pozun, G. Henkelman and C.B. Mullins, J. Catal. $282(2011) 278$.

8. J.A. Rodriguez, F. Illas, Phys. Chem. Chem. Phys. 14 (2012) 427.

9. T. Gomez, E. Florez, J.A. Rodriguez and F. Illas, J. Phys. Chem. C, 114 (2010) 1622.

10. S.T. Oyama, Catal. Today, 15 (1992) 179.

11. J.G. Chen, Chem. Rev. 96 (1996) 1477.

12. P. Liu and J.A. Rodriguez, J. Chem. Phys. 120 (2004) 5414.

13. A. Bruix, J.A. Rodriguez, P.J. Ramírez, S.D. Senanayake, J. Evans, J.B. Park, D. Stacchiola, P. Liu, J. Hrbek, F. Illas, J. Am. Chem. Soc. 134 (2012) 8968.

14. S. Posada-Perez, F. Viñes, P.J. Ramirez, A.B. Vidal, J.A. Rodriguez, and F. Illas, Phys. Chem. Chem. Phys. 2014, 16, 14912.

15. P. Liu, J.A. Rodriguez, T. Asakura, J. Gomes, and K. Nakamura, J. Phys. Chem. B, 109 (2005) 4575.

16. D. Cappus, C. Xu, D. Ehrlich, B. Dillmann, C.A. Ventrice, K. Al Shamery, H. Kuhlenbeck, and H.-J. Freund, Chem. Phys. 177 (1993) 533.

17. L.C. Grabow, A.A. Gokhale, S.T. Evans, J.A. Dumesic, and M. Mavrikakis, J. Phys. Chem. C, 112 (2008) 4608.

18. J.L.C. Fajin, M. Natalia, D.S. Cordeiro, and J.R.B. Gomes, J. Phys. Chem. A, 118 (2014) 5832. 
19. P. Liu and J.A. Rodriguez, J. Chem. Phys. 126 (2007) 164705.

20. A.A. Gokhale, J.A. Dumesic, and M. Mavrikakis, J. Am. Chem. Soc, 130 (2008) 1402.

21. J.L.C. Fajin, M. Natalia, D.S. Cordeiro, and J.R.B. Gomes, J. Phys. Chem. C, 116 (2012) 10120.

22. K. Mudiyanselage, S.D. Senanayake, P.J. Ramirez, S. Kundu, A. Baber, F. Yang, S. Agnoli, S. Axnanda, Z. Liu, J. Hrbek, J. Evans, J.A. Rodriguez, and D. Stacchiola, Topics in Catalysis, 58 (2015) 271.

23. J. Nakamura, J.M. Campbell and C.T. Campbell, J. Chem. Soc. Faraday Trans. 86 (1990) 2725.

24. C.V. Ovensen, P. Stoltze, J.K. Nørskov and C.T. Campbell, J. Catal. 134 (1992) 445.

25. J.A. Rodriguez, P. Liu, J. Hrbek, J. Evans, and M. Perez, Angew. Chem. Int. Ed. 46 (2007) 1329.

26. P. Liu and J.A. Rodriguez, J. Phys. Chem. B, 110 (2006) 19418.

27. S. Posada-Pérez, P.J. Ramirez, R.A. Gutierrez, D.J. Stacchiola, F. Viñes, P. Liu, F. Viñes, F. Illas, and J.A. Rodriguez, Catal. Sci. Technol. (2016) DOI: 10.1039/c5cy02143j.

28. D.J. Moon and J.W. Ryu, Catal. Lett. 92 (2004) 17.

\section{Figure captions:}

Figure 1: Left-side: $O$ 1s XPS spectra collected after dosing water to a clean MoC surface and to a carbide surface pre-covered by $0.15 \mathrm{ML}$ of platinum. Right side panel: Variation in the intensity of the $\mathrm{OH}$ features in the $\mathrm{O} 1 \mathrm{~s}$ XPS region as a function of $\mathrm{Pt}$ coverage on MoC. In all the experiments, $50 \mathrm{~L}$ of water were dosed at $300 \mathrm{~K}$.

Figure 2: Water-gas shift activity of $\mathrm{Pt} / \mathrm{MoC}$ as a function of Pt coverage. The reported values for the production of $\mathrm{H}_{2}$ and $\mathrm{CO}_{2}$ were obtained under steady-state after exposing the catalysts to a mixture of $\mathrm{CO}\left(20\right.$ Torr) and $\mathrm{H}_{2} \mathrm{O}(10$ Torr) at $450 \mathrm{~K}$. 
Figure 3: Arrhenius plots for the WGS reaction on $\mathrm{Pt} / \mathrm{MoC}, \mathrm{Pt} / \mathrm{TiC}(001)$ and $\mathrm{Cu} / \mathrm{TiC}(001)$ catalysts. The data for $\mathrm{Cu} / \mathrm{TiC}(001)$ was taken from ref. [22]. In the $\mathrm{Pt} / \mathrm{MoC}$ and $\mathrm{Pt} / \mathrm{TiC}(001)$ surfaces the platinum coverage was $0.15 \mathrm{ML}$. The reaction rates for each temperature $(410,425,435,450$, and $465 \mathrm{~K})$ correspond to steady-state measurements after exposing the catalysts to a mixture of $\mathrm{CO}$ (20 Torr) and $\mathrm{H}_{2} \mathrm{O}$ (10 Torr).

Figure 4: Estimated TOFs for the WGS on $\mathrm{Pt} / \mathrm{MoC}$ and $\mathrm{Pt} / \mathrm{TiC}(001)$ at different temperatures. The values correspond to steady-state measurements after exposing the catalysts to a mixture of $\mathrm{CO}$ (20 Torr) and $\mathrm{H}_{2} \mathrm{O}$ (10 Torr).

Figure 5: TOFs for the WGS on $\mathrm{Pt} / \mathrm{MoC}, \mathrm{Pt} / \mathrm{TiC}(001), \mathrm{Cu} / \mathrm{TiC}(001)$ [22], $\mathrm{Pt}(111)$ [7], $\mathrm{Cu}(111)[7,23]$ and $\mathrm{Cu} / \mathrm{ZnO}(000 \overline{1})$ [25]. The systems containing carbides are lowtemperature WGS catalysts.

Figure 6: Coverage of $\mathrm{O} / \mathrm{OH}$ on the surface of a Pt/MoC $\left(\theta_{\mathrm{Pt}_{\mathrm{t}}}=0.15 \mathrm{ML}\right)$ catalyst as a function of time and temperature. Post-reaction O 1s XPS was used to measure the $\mathrm{O} / \mathrm{OH}$ coverage. The values correspond to XPS measurements performed after exposing the catalyst to a mixture of $\mathrm{CO}\left(20\right.$ Torr) and $\mathrm{H}_{2} \mathrm{O}(10$ Torr) at 450 or $600 \mathrm{~K}$.

Figure 7: Left-side: $\mathrm{O}$ 1s XPS spectra collected after dosing $50 \mathrm{~L}$ of water to $\mathrm{MoC}$ and $\beta-\mathrm{Mo}_{2} \mathrm{C}(001)$ surfaces at $300 \mathrm{~K}$. Right side panel: Variation in the intensity of the $\{\mathrm{OH}+$ $\mathrm{O}$ \} features in the O 1s XPS region as a function of water exposure at $300 \mathrm{~K}$.

Figure 8: Coverage of $\mathrm{O} / \mathrm{OH}$ on the surface of $\mathrm{Pt} / \mathrm{MoC}$ and $\mathrm{Pt} / \mathrm{Mo}_{2} \mathrm{C}(001)$ catalysts $\left(\theta_{\mathrm{Pt}}=\right.$ $0.15 \mathrm{ML}$ ) as a function of time. Post-reaction O 1s XPS was used to measure the $\mathrm{O} / \mathrm{OH}$ coverage. The values correspond to XPS measurements performed after exposing the catalyst to a mixture of $\mathrm{CO}(20$ Torr $)$ and $\mathrm{H}_{2} \mathrm{O}(10 \mathrm{Torr})$ at $450 \mathrm{~K}$.

Figure 9: Product distribution after exposing fresh $\mathrm{Pt} / \mathrm{MoC}$ and $\mathrm{Pt} / \mathrm{Mo}_{2} \mathrm{C}(001)$ catalysts to a mixture of $\mathrm{CO}\left(20\right.$ Torr) and $\mathrm{H}_{2} \mathrm{O}(10$ Torr) at $435 \mathrm{~K}$. For comparison are also included the activities of plain $\mathrm{MoC}$ and plain $\beta-\mathrm{Mo}_{2} \mathrm{C}(001)$. 

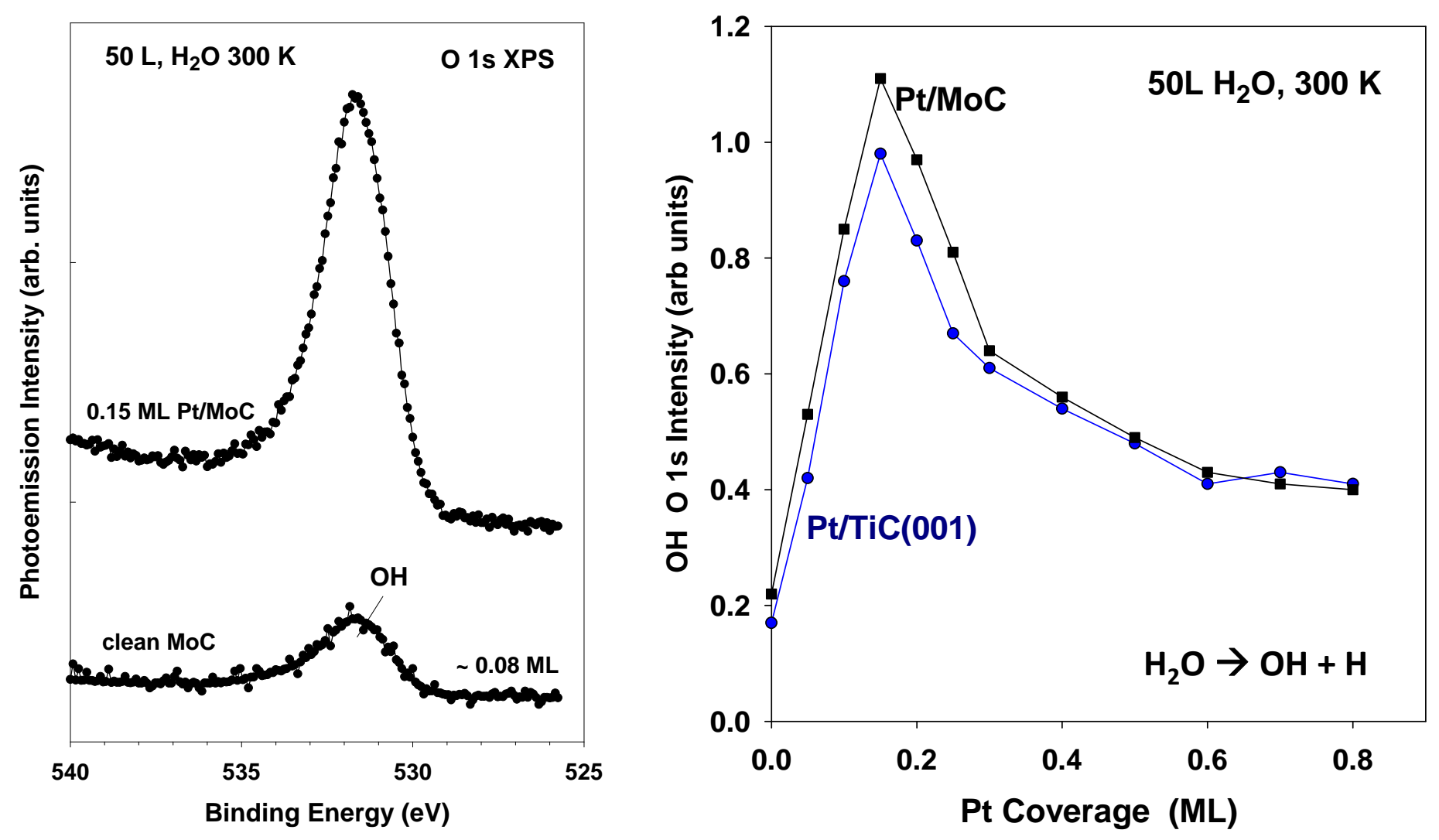

Figure 1 


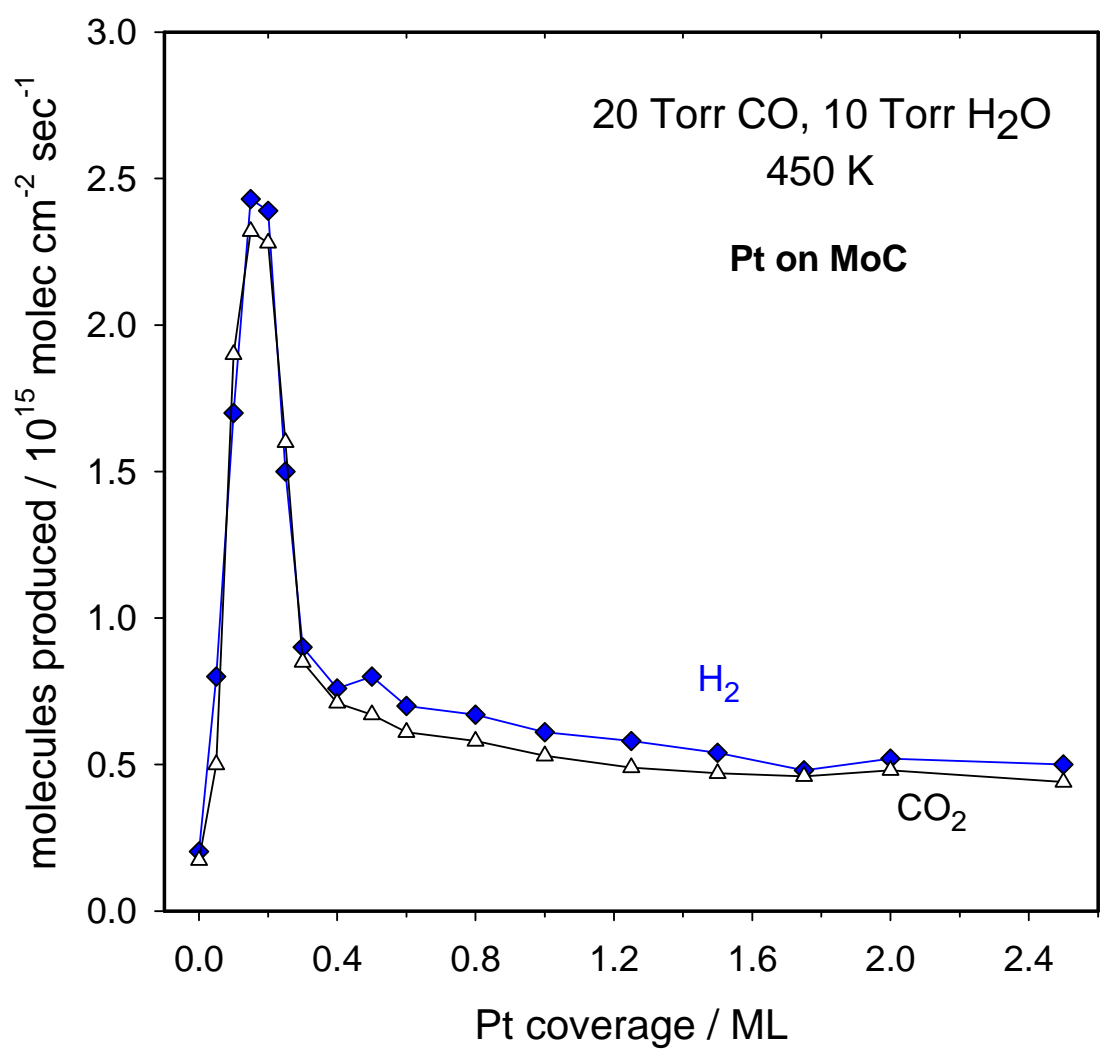

Figure 2 


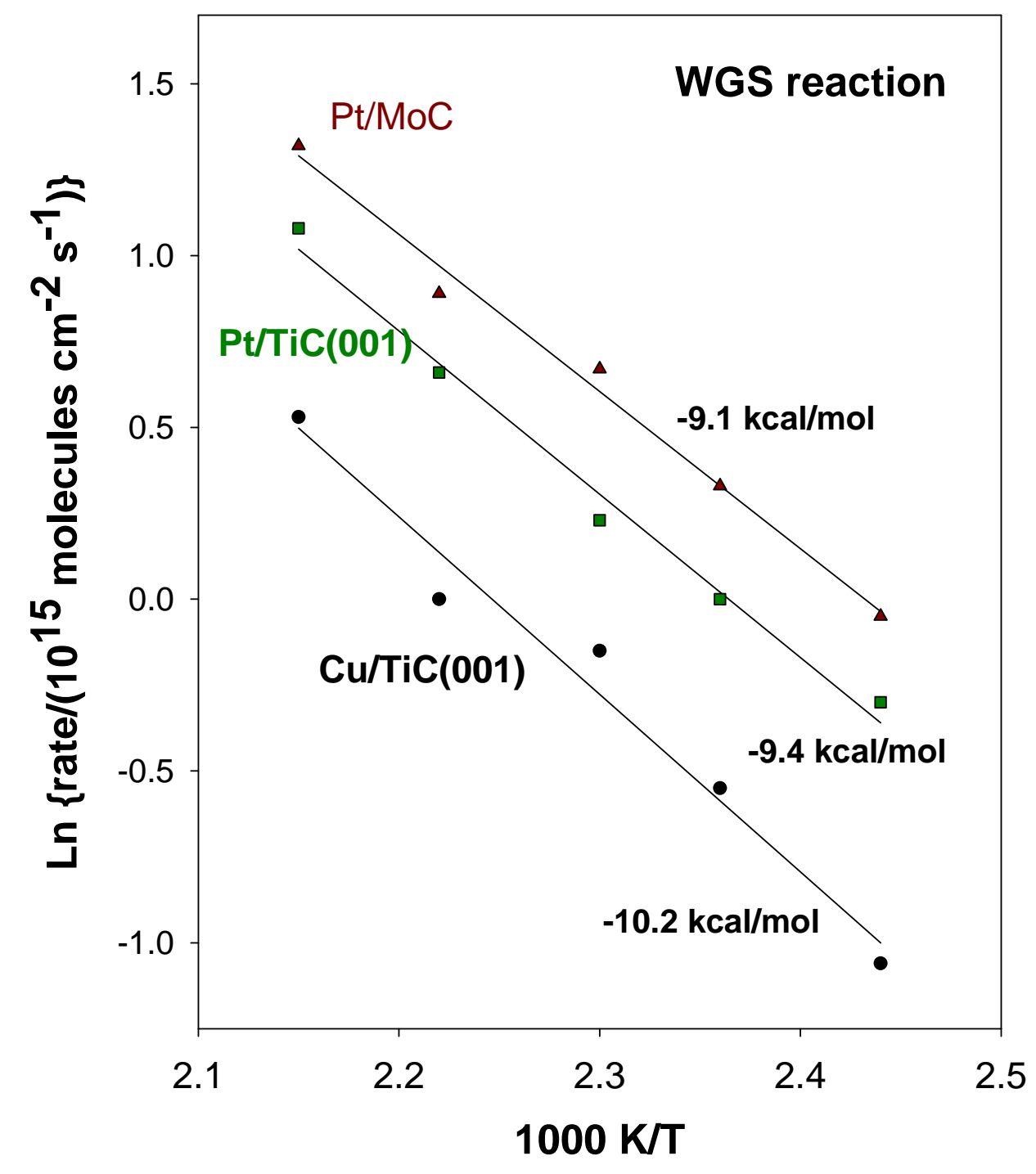

Figure 3 


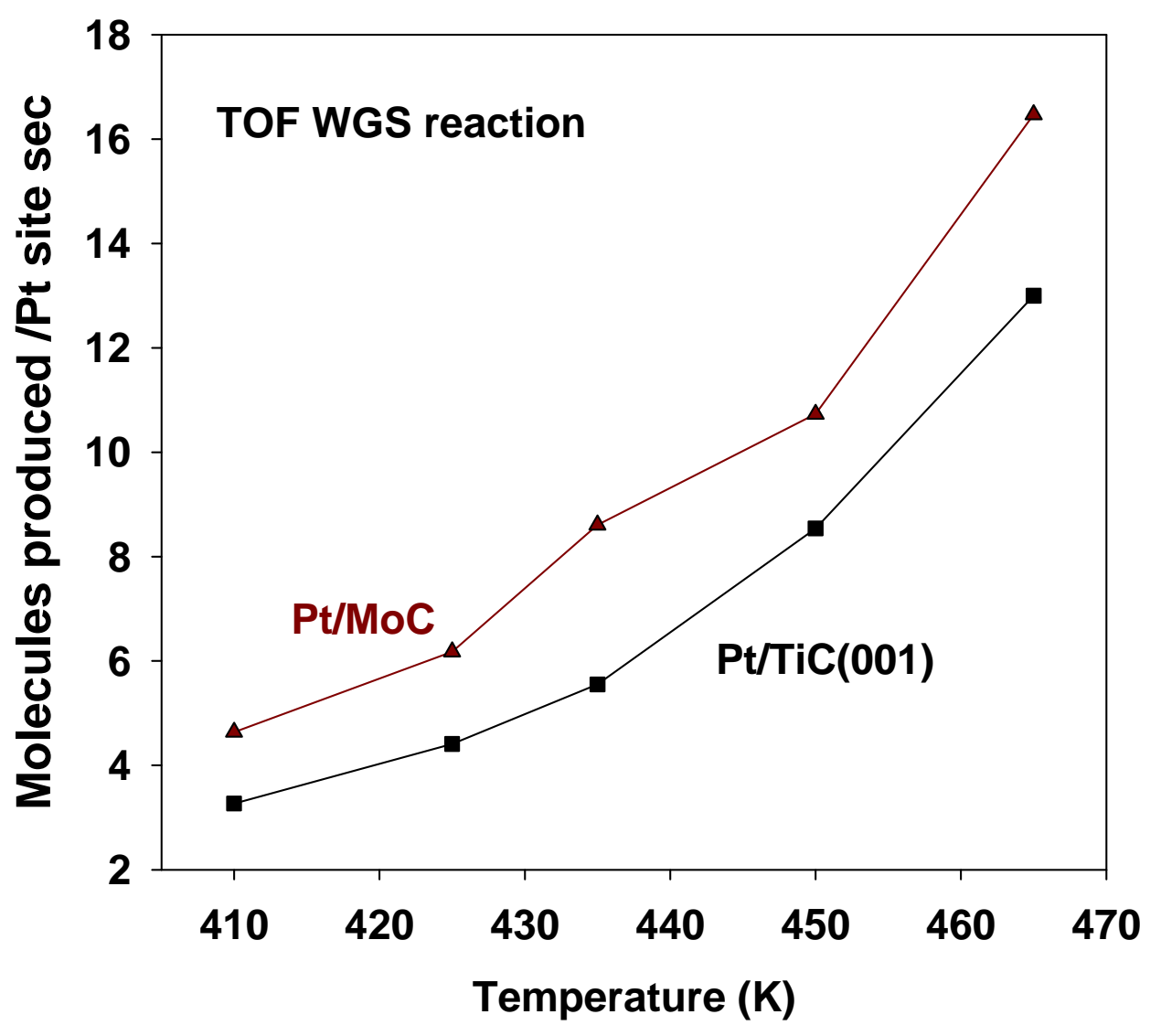

Figure 4 


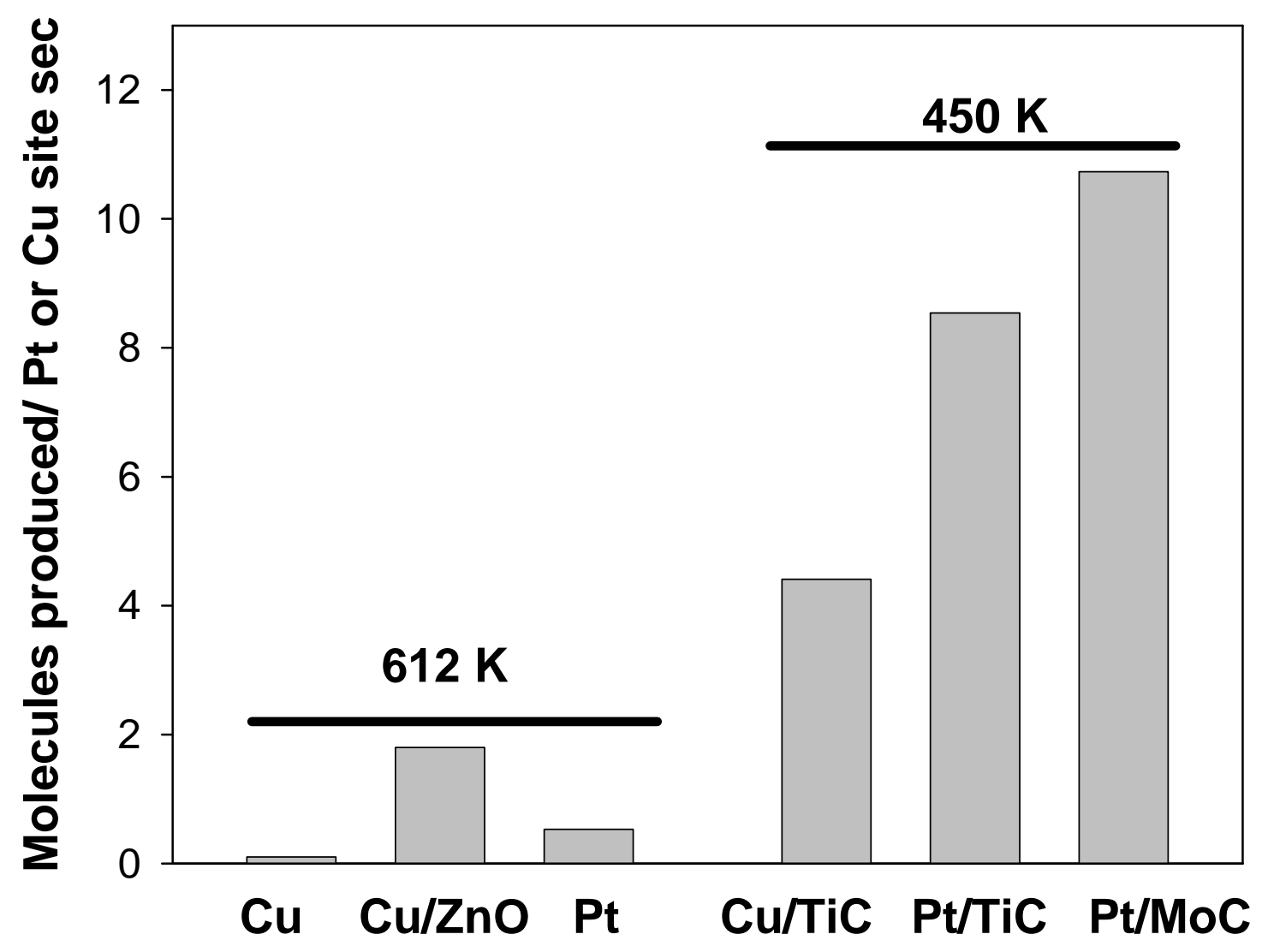

Figure 5 


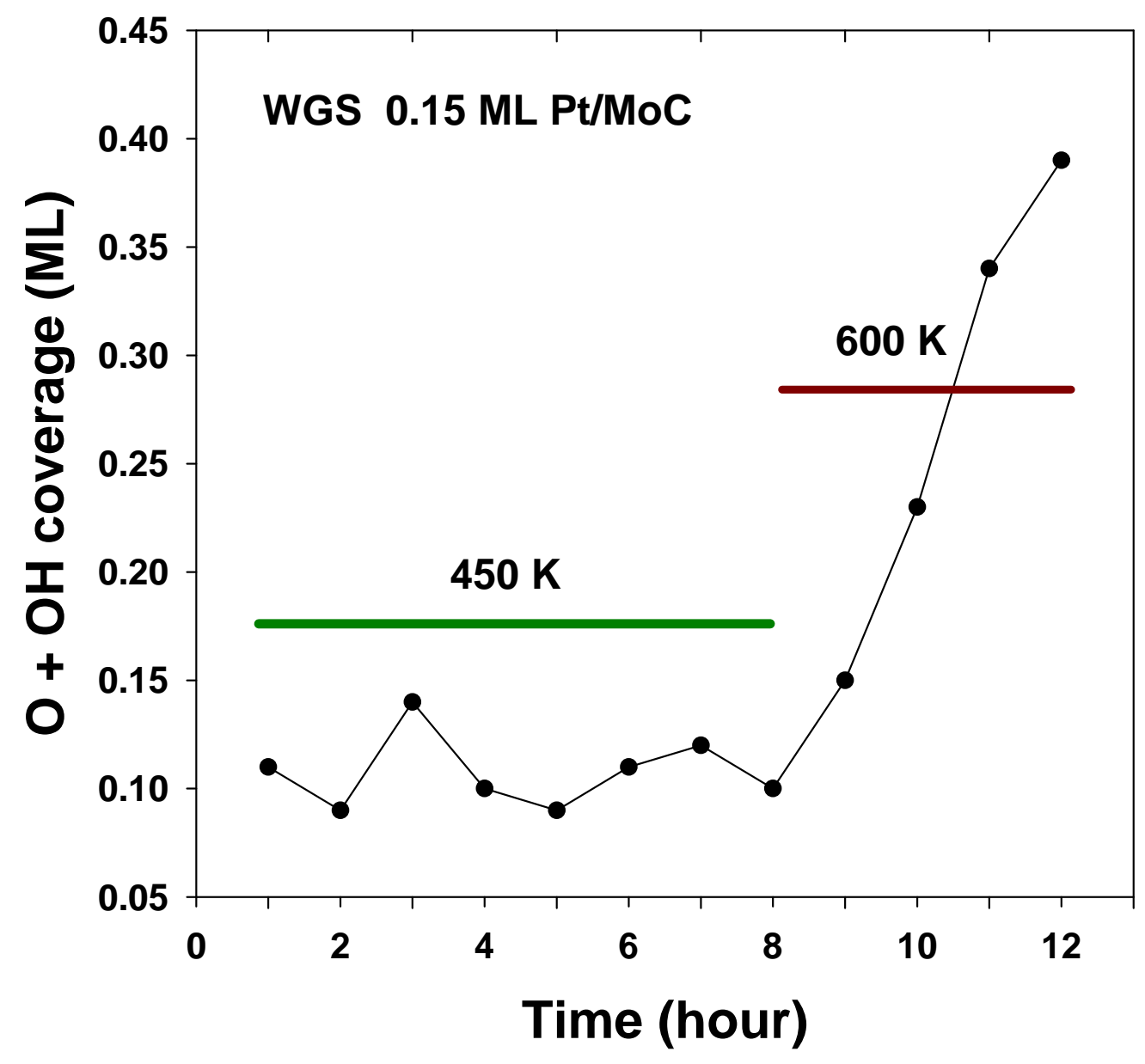

Figure 6 

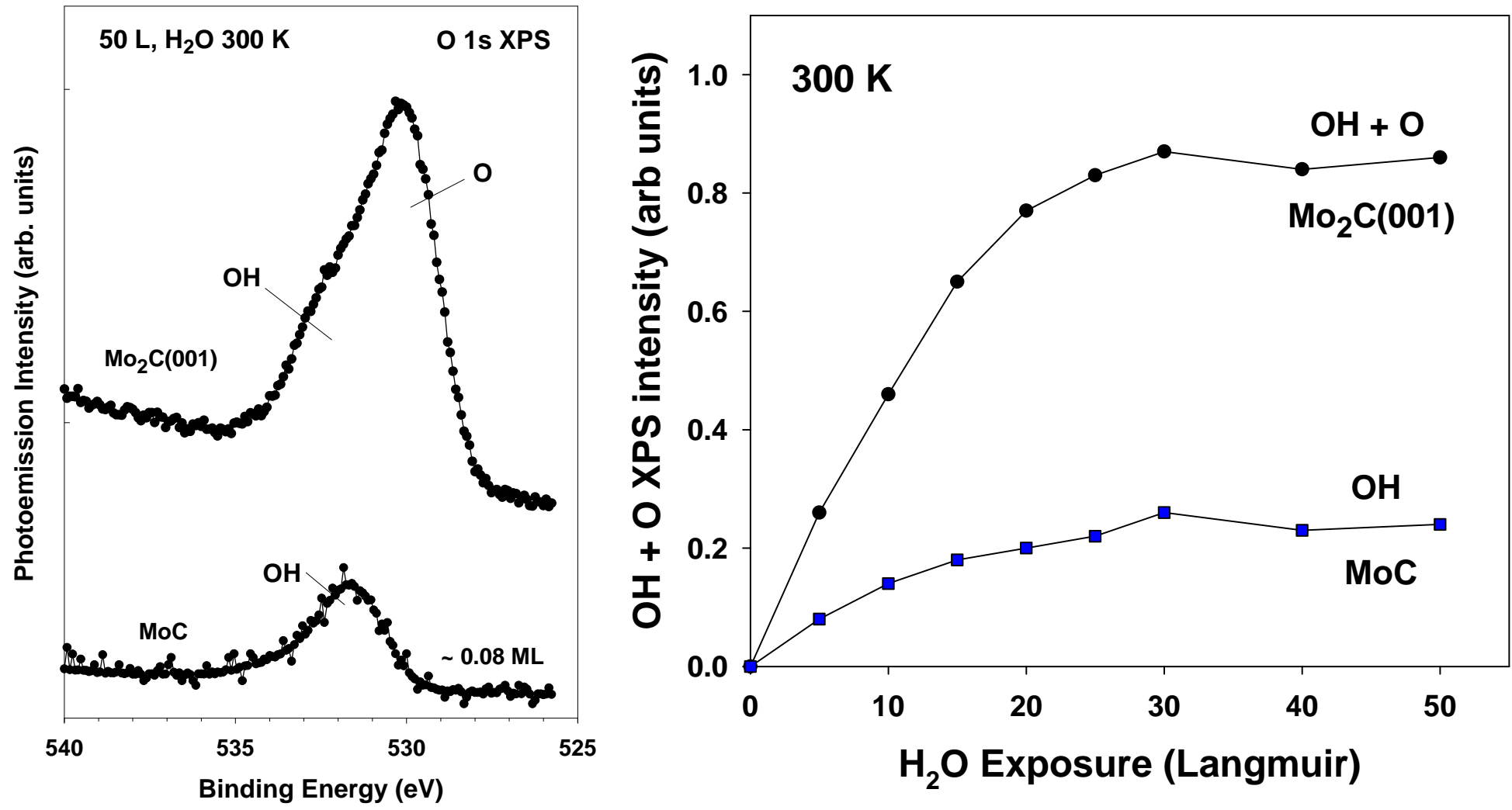

Figure 7 


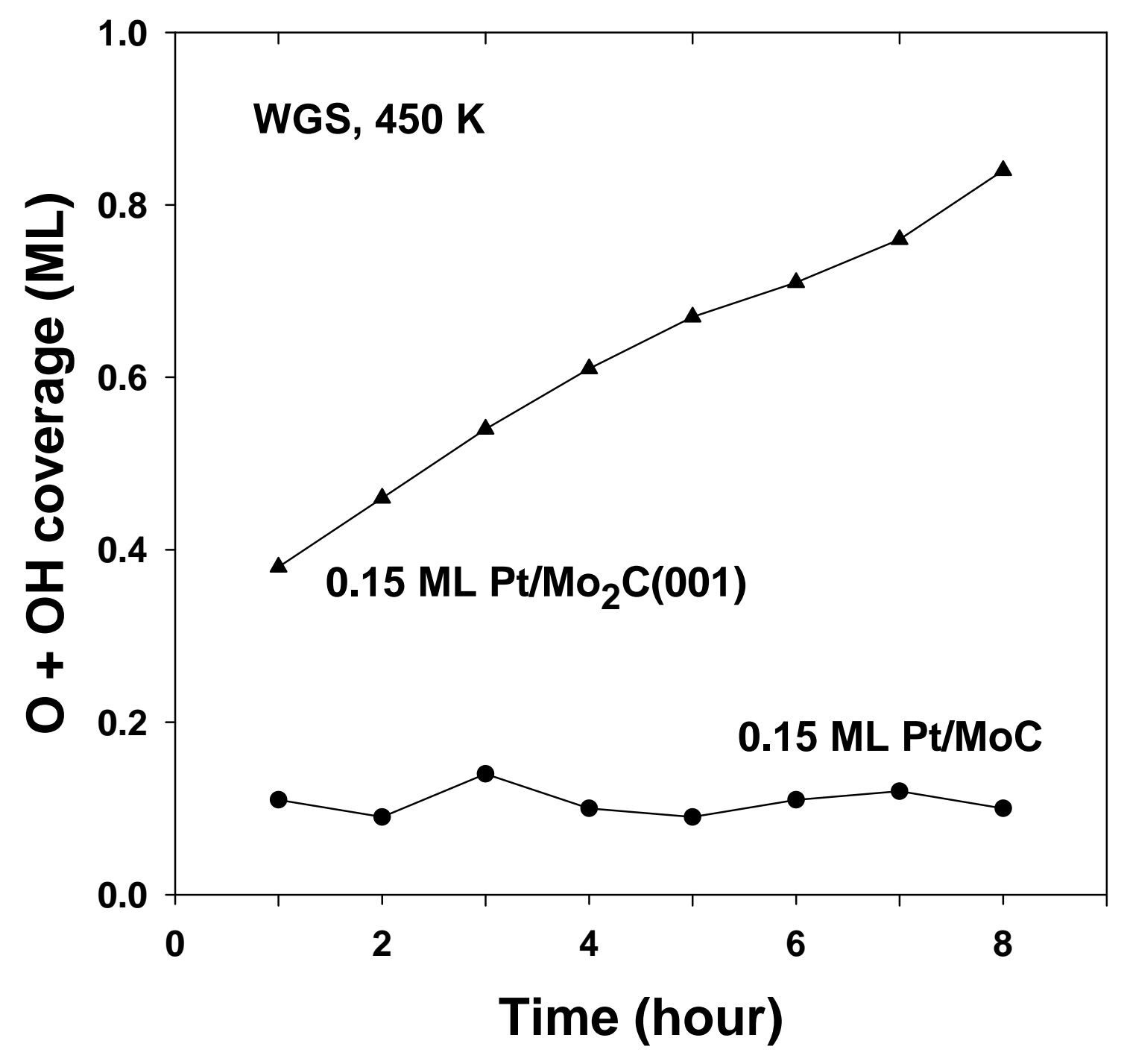

Figure 8 

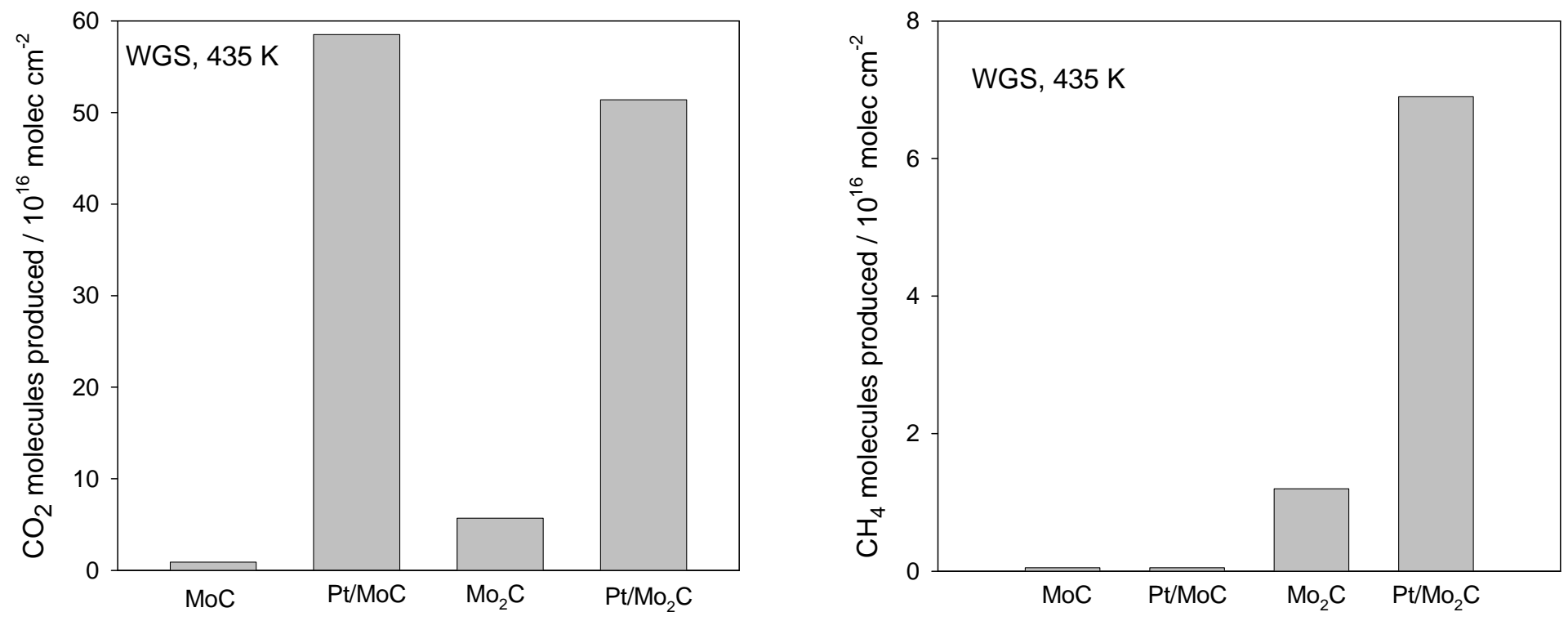

Figure 9 